\title{
LETRAMENTO ESTATÍSTICO: UMA EXPERIÊNCIA DE CAPACITAÇÃO PARA TUTORES A DISTÂNCIA DA UNOPAR
}

\author{
LONDRINA/PR MAIO/2018
}

\author{
Renata Karoline Fernandes - UNOPAR - renata.karoline@kroton.com.br \\ Lissandro de Sousa Falkowiski - UNOPAR - lissandro.falkowiski@kroton.com.br \\ Thiago Nunes Bazoli - UNOPAR - thiago.bazoli@kroton.com.br \\ Adriano Rosa Alves - UNOPAR - adriano.alves@kroton.com.br \\ Karen Hiramatsu Manganotti \\ - UNOPAR - karen.manganotti@kroton.com.br \\ Fernando Ciriaco \\ - UNOPAR - fernandod@pitagoras.com.br
}

Tipo: Relato de Experiência Inovadora (EI)
Categoria: Conteúdos e Habilidades
Setor Educacional: EDUCAÇÃO SUPERIOR

RESUMO

Este artigo apresenta inferências a respeito de uma experimentação com capacitação continuada, por meio de Letramento Estatístico, ofertada a tutores a distância da Universidade Pitágoras Unopar UNOPAR na modalidade de Educação a Distância. A experimentação ocorreu de forma que os tutores pudessem ter uma vivencia real como estudantes da Educação a Distância, ampliando a compreensão a respeito de todo o processo de ensino e de aprendizagem e focando na discussão e capacitação para a realização da mediação pedagógica. Para isso, utilizou-se o Letramento Estatístico como conteúdo para possibilitar o desenvolvimento de habilidades e competências relacionadas a organização, a análise e a interpretação de dados estatísticos, bem como tomada de consciência a respeito da importância da mediação no processo de ensino e aprendizagem na Educação a Distância.

Palavras-chave: Educação a Distância. Letramento Estatístico. 


\section{Introdução}

A Educação a distância - EaD tornou-se uma alternativa capaz de atender os anseios de formação superior para estudantes em todo o território nacional, rompendo barreiras de tempo e espaço. Entre os principais agentes envolvidos no processo de ensino e de aprendizagem nessa modalidade, destacam-se os professores, tutores e estudantes.

No que se refere ao papel do tutor a distância, que interage com os estudantes por meio da utilização de Tecnologias de Informação e Comunicação - TIC, um elemento crucial é a mediação pedagógica, ou seja, a maneira como interage com os estudantes e os efeitos que a interação pode causar no processo de ensino e de aprendizagem.

Este trabalho tem a intenção de discutir o desenvolvimento de uma capacitação continuada oferecida para tutores que trabalham na UNOPAR, evidenciando aspectos da elaboração, estruturação, operacionalização e contribuição da mesma para os participantes. O objetivo da capacitação é permitir que tutores, possam ter uma experiência real como estudantes da $\mathrm{EaD}$, de modo a vivenciar as potencialidades e dificuldades do processo de ensino e de aprendizagem nessa modalidade, bem como a tomada de consciência a respeito da importância da realização de uma mediação efetiva para potencializar a aprendizagem.

Para atingir o objetivo, escolheu-se como conteúdo gerador das atividades do curso de capacitação continuada o Letramento Estatístico, visto que esse tema é pertinente a função da tutoria, pois é potencialmente capaz de auxiliar na aprendizagem da organização de dados, utilização de diferentes representações para a mesma informação, bem como desenvolvimento do pensamento lógico-matemático, análise de dados representados por meio de quadros e tabelas. O desenvolvimento de tais habilidades e competências podem favorecer o processo de mediação e nas demais funções dos tutores a distância na organização dos processos, no que diz respeito a catalogar ou organizar em gráficos e tabelas as principais dúvidas dos estudantes, ou ainda o conteúdo que mais e menos apresentaram dificuldades, por exemplo.

\section{Objetivos}

O objetivo desse trabalho é apresentar como desenvolveu-se uma capacitação continuada para tutores a distância por meio do Letramento Estatístico e possíveis contribuições para a formação dos envolvidos.

\section{Referencial Teórico}


A educação a distância de acordo com o Decreto no 9.057, de 25 de Maio de 2017, é considerada como modalidade de ensino em que a mediação didático- pedagógica nos processos de ensino e de aprendizagem utilizam-se de meios tecnológicos para ser efetivada, em que estão envolvidos profissionais qualificados e atendendo especificações de políticas de acesso a instituição e avaliação, de modo que os estudantes e os profissionais da educação realizem atividades em tempos e lugares distintos, de modo que, propicie a maior articulaão entre o real, local e global, respeitando a subjetividade e a particição democrática nos proessos de ensino e de aprendizagem, em tempos e locais diversos (BRASIL, 2016).

A respeito do tutor a distância, este tem o papel de acompanhar, motivar, orientar, estimular e mediar a aprendizagem dos estudantes, por meio da utilização de técnicas e meios adequados para a facilitação da aprendizagem, propiciando por meio de diálogos, a reflexão autônoma dos estudantes, discussões a respeito dos conteúdos abordados nos cursos, respeitando diversificações culturais e/ou regionais, exercendo atividades em dimensão técnica, gerencial e pedagógica (FERREIRA; REZENDE, 2003). Para que o tutor a distância possa atuar exercendo suas funções nas dimensões técnicas, gerenciais, no sentido de auxiliar no gerenciamento das atividades de auto estudo dos alunos e também pedagógica, o mesmo deve estar capacitado para a realização da mediação pedagógica dinâmica e eficiente. Nesse trabalho, compreende-se mediação pedagógica de acordo com Masetto (2000), considerando-a como uma atitude, um comportamento do profissional da educação de incentivar e motivar para a aprendizagem, como ponto entre o aprendiz e a aprendizagem, realizada por meio do diálogo, troca de experiências, discussões e argumentações, ainda:

A mediação pedagógica, a comunicação e a interação nos ambientes virtuais ainda estão em processo de construção na maioria dos modelos de $\mathrm{EaD}$, com muitas experiências e abertura para criatividade e inovações e que sugerem um esforço maior de investigação, dada a variedade de soluções experiências [...] os AVEA (Ambientes Virtuais de Ensino e Aprendizagem) se constituem em espaços vivos, flexíveis, orgânicos, que podem ser modificados constantemente, além de acumular uma quantidade de dados e de trocas enunciativas de difícil manipulação (MASETTO, 2000 p.142) .

Tendo em vista a importância do tutor a distância e da mediação para a aprendizagem na EaD e considerando que um modo de proporcionar a reflexão dos responsáveis pela realização da mediação é por meio da empatia, ou seja, se colocando no lugar do estudante da Educação a Distância, para que seja possível compreender de forma vivencial como a mediação feita por ele impacta positiva ou negativamente na vida dos 
estudantes, quais as melhores técnicas para a realização da mediação e também abordagem dos estudantes, propôs-se a capacitação continuada do Letramento Estatístico, proporcionando aos tutores experiências reais como estudantes da Educação a Distância.

A capacitação continuada ofertada para tutores a distância, foi planejada a partir da integração entre dois programas de Pós-graduação sediados em cidades distintas, visando entre outros, refletir a respeito do processo de mediação pedagógica desenvolvida pelos tutores, participantes da capacitação. Para viabilizar esse processo formativo, o contexto foi o Letramento Estatístico, pois este traz conhecimentos, essenciais para a formação acadêmica, profissionais e também para o exercício da cidadania (GIORDANO, 2016).

A Estatística é uma ciência, um ramo da Matemática, que tem seus conteúdos aplicados em distintas profissões, tendo ainda, potencial para desenvolver o senso crítico, organizar os dados, analisá-los e favorecer tomadas de decisões baseadas em análises objetivas, elaboração de argumentos conscientes, de modo a favorecer aspectos profissionais, favorecer o desenvolvimento do senso crítico, por meio da compreensão de dados presentes em pesquisas, frequentemente apresentadas em pesquisas, visto que, sem ter ao mesmo um letramento estatísticos, as pessoas não possuem ferramentas necessárias para analisar informações divulgadas e desconfiar de números apresentados (CAZORLA; CASTRO, 2008). De acordo com Soares (2005) o termo letramento começou a ser empregado de forma relacionada com a educação, por volta de 1986, de modo que o sujeito letrado em algo é o indivíduo capaz de realizar leitura, escrita e comunicar-se na área de seu letramento. No que se refere a área da Educação Estatística, compreende-se o termo Letramento Estatístico, segundo o autor Wallman (1993) que o trata como sendo a capacidade de compreender e avaliar situações pessoais e profissionais de forma crítica por meio da realização de dados e resultados estatísticos que permeiam a vida cotidiana das pessoas.

A escolha do tema Letramento Estatístico como conteúdo base para a realização de uma capacitação continuada para tutores, tendo interesse em proporcionar reflexões a respeito da mediação no processo de ensino e aprendizagem, deu-se pois:

[...] esse tipo de letramento (o letramento estatístico) deve permitir com que as pessoas fizessem mais do que apenas ler os dados, mas criticar e propor interpretações alternativas a um conjunto de dados. Assim, o letramento estatístico não resolverá todas as questões problemáticas, mas poderá contribuir para o desenvolvimento de cidadãos ativos e críticos que possam ler e interpretar estatísticas que fazem conexões com 
diferentes áreas, o que poderiam facilitar as análises das realidades nas quais vivem (MONTEIRO, 2006).

Nesse sentido, compreende-se que o letramento estatístico é um tema com potencial para a capacitação voltada a mediação pedagógica e ainda, pertinentes para as mais diversas áreas de formação inicial dos tutores, visto que na Universidade em que ocorre a capacitação, os tutores são formados em diferentes graduações das áreas de licenciatura, bacharelado e cursos superiores de tecnologia, proporcionando assim, aprendizagem que possam favorecer a mediação pedagógica, com o desenvolvimento do senso crítico, organização e análise de dados em tabelas e gráficos, o que auxilia na organização do tutor com relação a realização de suas atividades profissionais diárias, contribuindo também para o desenvolvimento de cidadãos críticos.

Após a retomada teórica a respeito dos principais pontos desse relato de experiência, inicia-se a descrição dos procedimentos metodológicos para a elaboração deste trabalho, bem como métodos para a construção da capacitação.

\section{Procedimentos Metodológicos}

Nesse trabalho apresenta-se um relato de experiência, tendo caráter predominantemente qualitativo e sendo do tipo descritivo exploratório. Por se tratar de uma pesquisa descritiva, a mesma caracteriza-se pela inferência direta a respeito do objeto analisado (GIL, 1999), no caso o projeto de capacitação Letramento Estatístico, visando compreender e proporcionar maior familiaridade com os elementos que compõe a situação.A respeito da característica descritiva do trabalho, tem-se a que mesma busca descrever o fenômeno estudado de acordo com a variação de tempo e espaço (MARCONI; LAKATOS, 1991). Com relação ao objetivo do trabalho em descrever o Letramento Estatístico, a parte descritiva relaciona-se com a exemplificação dos procedimentos realizados, com os instrumentos utilizados e o modo como o mesmo se desenvolveu.

Ainda, utilizou-se para fundamentação do relato, procedimentos característicos de estudo de caso, que para Goog e Halt (1979), tem como característica a compreensão de situações que podem ou não ser generalizadas, tendo como princípio o levantamento e organização de dados, preservando o objeto estudado. Para a realização do estudo de caso, como citado anteriormente, utilizou-se a capacitação Letramento Estatístico desenvolvido na Universidade Pitágoras Unopar e aplicado à 283 tutores a distância.

\section{Discussão dos resultados.}


Para o desenvolvimento da capacitação continuada voltada aos tutores a distância, inicialmente buscou-se verificar quais são os conteúdos estatísticos que tivessem potencial para auxiliar os participantes na realização de tarefas cotidianas e laborais, desenvolvimento do senso crítico e pudessem gerar possibilidades para a efetivação da mediação pedagógica. Assim, os pesquisadores envolvidos no projeto optaram pelos conceitos de organização de dados e análises dos mesmos por meio de tabelas e gráficos, moda, média e mediana e desvio padrão.

Os conteúdos foram organizados em três módulos, de modo que até o momento foram aplicados somente dois. O módulo I tratou dos conceitos de organização e análise de dados em gráficos e tabelas, moda, média e mediana. No módulo II houve a construção do conceito de desvio padrão e o módulo III, com acontecimento previsto para o início do segundo semestre de 2018, é destinado para a elaboração de um artigo pelos tutores participantes, de modo que deverão fazer levantamento de dados de uma situação de interesse, aplicar os conhecimentos desenvolvimentos por meio do letramento estatístico e redigir um artigo a respeito. Nos módulos I e II foram desenvolvimentos por meio da utilização da plataforma Moodle, de modo que as explicações e conceitualizações estavam presentes em forma de textos digitais e vídeo aulas, tendo o conteúdo abordado com a utilização de cenários reais, situações cotidianas, como o desenvolvimento de atividades por meio da análise de uma conta de água, escolhe do carro que melhor atende as necessidades e variações de temperatura. $\mathrm{Na}$ figuras I temos um exemplo da organização dos conteúdos no Ambiente Virtual de Aprendizagem - AVA:

Figura 1: Conteúdos no AVA.
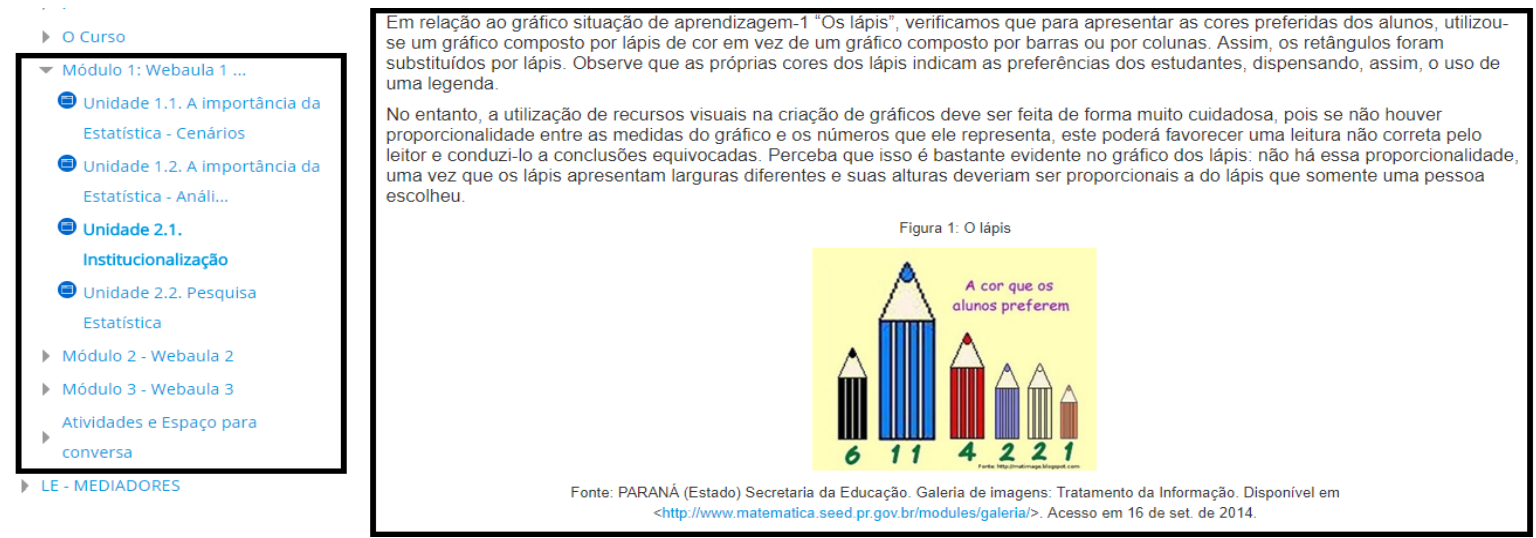

Fonte: Dos autores (2018).

No lado esquerdo, o participante da capacitação selecionava o Módulo que desejava estudar da capacitação, após a realização das atividades do módulo I, foi disponibilizado 
o módulo II e ao término, será disponibilizado o módulo III. Ao realizar a seleção, o conteúdo fica disponibilizado ao lado, para o estudo.

Os tutores a distância, que desenvolveram papel de estudantes da Educação a Distância para a realização das atividades da capacitação, mantiveram contato com os professores responsáveis pela mediação, por meio do fórum de discussão e sistema de mensagem.

No fórum de discussão, os tutores podiam inserir suas dúvidas e contribuições que eram compartilhadas com todo o grupo, pois nesse ambiente todos os envolvidos tinham acesso as postagens. Com relação ao sistema de mensagens, este era privado, ou seja, as mensagens encaminhadas eram vistas somente pelo tutor que encaminhou e pelo professor responsável.

Para acessar o fórum de discussão, o tutor clica em Atividades e Espaço para conversa, sendo este o ambiente para troca de experiências, discussão das atividades propostas ao longo dos módulos e esclarecer dúvidas a respeito dos conteúdos. Na figura 2 apresenta-se a forma como os fóruns de discussão ficam disponíveis aos tutores e professores.

Figura 2: Fórum de discussões
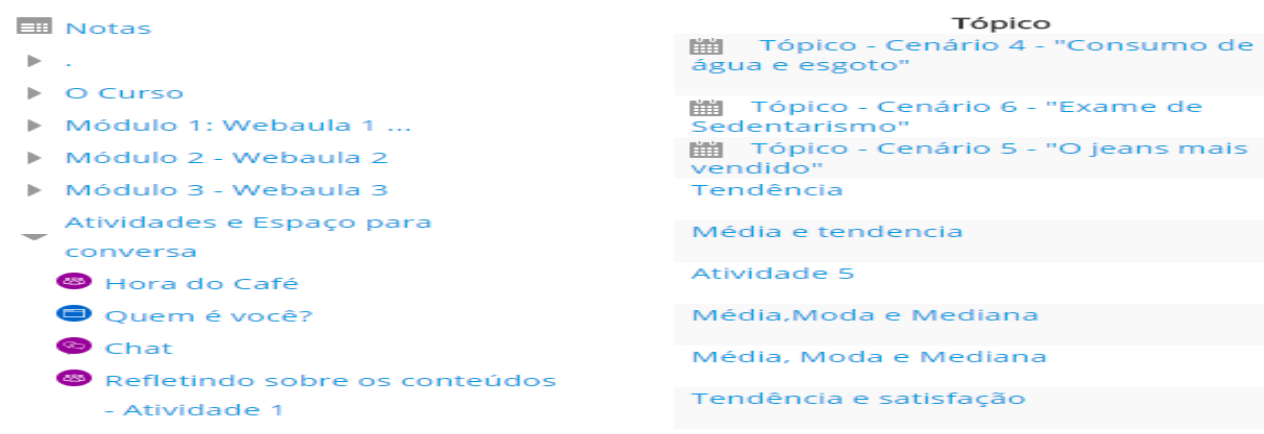

Fonte: Dos autores (2018).

A mediação pedagógica com relação as atividades desenvolvidas e conteúdo da capacitação foi tratada exclusivamente de forma digital, mesmo modo que acontece com os estudantes de graduação que optam pela Educação a Distância. Assim, os tutores puderam experienciar a importância da realização da mediação pedagógica feita de forma coerente e o quanto ela contribuiu para o processo de ensino e de aprendizagem.

Entre o desenvolvimento das atividades de conteúdo específico de Letramento Estatístico, houve encontros presenciais com pesquisadores que desenvolveram a 
capacitação para a discussão a respeito da mediação pedagógica. Esses encontros fizeram-se necessários para a sistematização do tema mediação pedagógica, um dos focos principais da capacitação. Após realizada a apresentação dos elementos da capacitação, e a forma como foi estruturada e conduzida, na próxima seção inicia-se a discussão dos resultados parciais da capacitação, visto que, ela ainda está em desenvolvimento.

Com relação a contribuição da capacitação para a formação dos participantes, infere-se que a mesma existiu, visto alguns dos relatos coletados por meio de produção textual e também participações no fórum de discussão. Nas figuras abaixo, nas quais os nomes dos participantes foram retirados para garantir seu anonimato, apresentamos algumas exemplificações que baseiam tais inferências:

Figura 3: Contribuição 1 do participante.

Re: A importância da Estatística

por Lu terça. 18 jul 2017. 16:41

Oras pessogi

Após a leitura da web aula 1, podemos concluir que a estatistica atualmente desempentha um papel indispensável para qualquer

Fonte: Dos autores (2018).

Fugura 4: Contribuição 2 do participante

Re: A importância da Estatística

por An: $\quad$.terça, 18 Jul 2017, 16:54

É notório que a estatistica está presente em múltiplas tarefas do nosso dia a dia e se faz muito importante para toda sociedade. Dentre estas múltiplas tarefas, destacam-se as atividades financeiras e o tempo do nosso dia.

Dentre atividades financeiras, destaco as variações médias dos índices aplicados no mercado, para analisar por exemplo a taxa de reajuste do aluguel de imóveis, o IGPM - ÍNDICE GERAL DE PREÇOS DO MERCADO, que apurando as variações de preço da contul

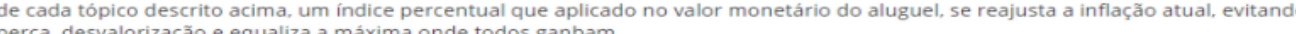

Reflito que sem a transformação e apurações das informações, estariamos muito atrasados em nosso desenvolvimento, e acredito que a apuraçăo das informaçôes quantitativas e qualitativas estão cada dia mais apurado. com a utilizaçăo da tecnologia. algo que no passado não era possivel, trazendo assim inumeros beneficios para todos.

Mais que trazer os dados, é importante saber interpretar estas informações, para tomada de decisões mais assertivas. Na história em quadrinhos onde Fernando e Alice discutem sobre as eleições em suas cidades, ela fica em dúvida sobre o empate técnico nas

pesquisas e sua margem de confiança, que representa uma amostra em um intervalo de populaçăo, ou seja, se separarmos por conglomerados esta população, a possibilidades hipotéticas de que partes destas pessoas terão a mesma opinião. Se não atentarmos do que se trata as informaçōes apresentadas muitas decisōes podem ser dolorosas.

Tenho grande expectativa e dúvidas em relação ao bem-estar da sociedade, onde parte não observa que o tempo está passando, e se faz necessário organiza-lo, além de um simples olhar no relógio.

\section{Link direto Mostrar principst}

Editor

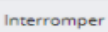

Fonte: Dos Autores (2018).

Por meio desses relatos, percebe-se que houve a constatação da importância da aprendizagem de conceitos estatísticos para aplicação em diversas profissões, visto que 
a mesma é utilizada em diferentes contextos e ainda, houve a relação da estatística com o bem-estar social, pois a mesma é necessária para organização e representação de dados, bem como, auxilia no desenvolvimento do pensamento crítico.

Figura 5: Contribuição 3 do participante.

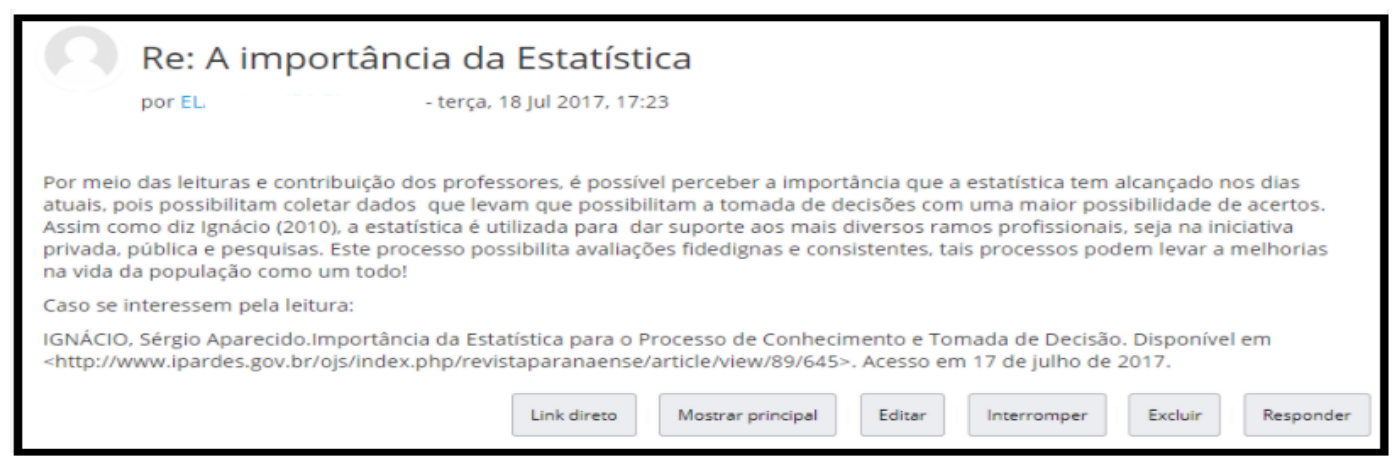

Fonte: Dos Autores (2018)

Novamente, percebe-se a relação que os participantes do curso de capacitação estabeleceram com a estatística e com situações reais, a importância de conhecer elementos estatísticos, ou seja, ser letrado estatisticamente, para que possam analisar de modo mais crítico informações de revistas e jornais. Outro fato importante que se apresenta na figura 5, é que os próprios participantes da capacitação podiam realizam sugestões de estudo aos demais participantes, como foi o caso, em que o tutor sugeriu um artigo para a leitura.

\section{Considerações Finais}

Este trabalho teve a intenção principal de relatar uma experiência aplicada na Universidade Pitágoras Unopar, por meio da capacitação continuada de todos os tutores a distância na realização do curso de Letramento Estatístico. A escolha do Letramento Estatístico como contexto para o desenvolvimento, treino, análise e aprimoramento da mediação pedagógica, deu-se devido considerarmos que a Estatística é funcional para diversas profissões, bem como, aplicável em contextos reais e no dia a dia de toda a população.

Compreende-se que a capacitação citada nesse trabalho, atingiu seus objetivos, pois desenvolveu o processo de ensino e aprendizagem de temas relevantes, bem como, proporcionou momentos de discussão e reflexão a respeito do processo de mediação pedagógica, sendo essa, fundamental para o bom desenvolvimento dos estudantes da Educação a Distância e ainda, uma das principais funções do tutor a distância. 


\section{Referências}

BATTISTI, de S; ALBA, R. SILVEIRA, S. A; ROESLER, J. Mediação Pedagógica na Educação a Distância: entre enunciados teóricos e práticas construídas. Revista Diálogo Educacional, 2008.

BRASIL. Ministério da Educação. Portaria Normativa n 11, de 20 de junho de 2017b.

CAZORLA, I.; CASTRO, F. O papel da estatística na leitura do mundo: o letramento estatístico. Publ. UEPG Humanit. Sci., Appl. Soc. Sci., Linguist., Lett. Arts, Ponta Grossa, v.16 (1). Jun, 2008.

FERREIRA, M.M.S. e REZENDE. R.S.R. O trabalho de tutoria assumido pelo Programa de Educação a Distância da Universidade de Uberaba: um relato de experiência. 2003.

GIL, A. C. Métodos e Técnicas de Pesquisa Social. Atlas. São Paulo, 1999.

GIORDANO, C. C. O desenvolvimento do letramento estatístico por meio de projetos: um estudo com alunos do Ensino Médio. 2016. 155 f. São Paulo, 2016.

GOODE W.J, HATT P. K. Métodos em pesquisa social. 5a ed. São Paulo: Companhia Editora Nacional;1979.

MARCONI, M. de A; LAKATOS, E. M. Metodologia do Trabalho Cientifico. Atlas. $6^{\underline{a}}$ edição. São Paulo, 1991.

MASETTO, M. T. Novas tecnologias e mediação pedagógica. São Paulo: Papirus, 2000. p. 133-173.

MONTEIRO, C. E. F. Letramento Estatístico: conceituações e implicações para a Educação Estatística. Encontro Paraibano de Educação Matemática, 2016.

SOARES, M. Alfabetização e letramento: caderno do professor. Belo Horizonte: Ceale/FaE/UFMG, 2005. 